\title{
Circulatory effects of expiratory flow-limited exercise, dynamic hyperinflation and expiratory muscle
} pressure

\author{
P.T. Macklem
}

ABSTRACT: This article reviews recent research in normal subjects exercising with and without expiratory flow limitation at $\sim 1 \mathrm{~L} \cdot \mathrm{s}^{-1}$ imposed by a Starling resistor in the expiratory line, and in patients with chronic obstructive pulmonary disease (COPD), using optoelectronic plethysmography to measure respiratory kinematics, combined with mouth, pleural and abdominal pressure measurements, to assess work of breathing and respiratory muscle performance.

In normal subjects, flow-limited exercise resulted in the following: 1) Impaired exercise performance due to intolerable dyspnoea; 2) hypercapnia; 3) excessive respiratory muscle recruitment; 4) blood shifts from trunk to extremities; 5) a 10\% reduction in cardiac output and a $5 \%$ reduction in arterial oxygen saturation, decreasing energy supplies to working respiratory and locomotor muscles. In both normal subjects and in COPD patients, dynamic hyperinflation did not always occur. Those patients that hyperinflated had worse lung function and less work of breathing, but better exercise performance than the others, in whom expiratory muscle recruitment prevented dynamic hyperinflation at the cost of increased work of breathing and excessive oxygen cost of breathing. This established an early competition between respiratory and locomotor muscles for available energy supplies.

Dynamic hyperinflation is a better exercise strategy in chronic obstructive pulmonary disease than expiratory muscle recruitment, but the benefit it confers is small.

KEYWORDS: Chronic obstructive pulmonary disease, hypercapnia, respiratory muscles, ventilatory pump, work of breathing

I n chronic obstructive pulmonary disease (COPD), expiratory flow limitation (EFL) during exercise is common and leads to both dynamic hyperinflation (DH) and expiratory muscle recruitment. This was first reported by POTTER et al. [1] 35 yrs ago, who found that some patients with COPD hyperinflated, while others did not. They also observed strong recruitment of expiratory muscles in some patients and speculated that high expiratory pressures might have adverse cardiovascular effects. These findings were later confirmed by DoDD et al. [2] and ALIVERTI et al. [3]. While it is now well established that $\mathrm{DH}$ is an important cause of exercise limitation in COPD [4], the role of high expiratory pressures on cardiovascular function is still unclear. This article will review recent research in this area.

\section{STUDIES OF EFL IN NORMAL SUBJECTS DURING EXERCISE}

Normal subjects exercising while breathing through a Starling resistor in the expiratory line, which limits expiratory flow to $\sim 1 \mathrm{~L} \cdot \mathrm{s}^{-1}$, make an interesting model of COPD. The flow limitation markedly limits exercise performance to $\sim 65 \%$ of control maximal exercise workload $[5,6]$. This limitation is due to intolerable dyspnoea $[5,7]$, accompanied by marked hypercapnia [6, 7]. There is strong recruitment of expiratory muscles but $\mathrm{DH}$ was not a prominent feature; it occurred in some subjects but only at the highest level of flow-limited exercise. Up to that point there was a normal reduction in end-expiratory lung volume (EELV). Other subjects had a normal progressive reduction in EELV with increasing exercise workload and with no DH at all $[5,6]$. Thus, important
CORRESPONDENCE

P.T. Macklem

PO Box 250

Lansdowne

ON

KOE 1 LO Canada

Fax: 390223999000

E-mail:ptm01@hotmail.com 
clinical features of COPD are reproduced. This model allows experiments to be performed in trained normal subjects that cannot be performed in patients. Such experiments have led to insights and hypotheses on mechanisms of exercise limitation in COPD.

These investigations have utilised a three-compartment chest wall model [8], in which the ribcage is partitioned into the lung-apposed, or pulmonary, ribcage and the diaphragmapposed, or abdominal, ribcage, with the third compartment being the abdomen. The model allows quantification of individual contributions to breathing of the diaphragm, the inspiratory and expiratory ribcage muscles and the abdominal muscles [8]. It requires measurement of volume displacements of all three chest wall compartments. When the threecompartment model was first introduced, the technology for measuring these volumes was barely adequate for the task during quiet breathing and was inadequate for exercise; however, this changed as a result of the development of optoelectronic plethysmography (OEP). This new technology tracks the three-dimensional motion of 89 reflective markers attached to the chest wall, front and back from clavicles to pubis. Using Gauss's theorem, the volume of the chest wall and its compartments are continually calculated with a high degree of accuracy [9]. When these displacements are combined with measurements of oesophageal, gastric and mouth pressures, quantification of the pressures developed (as an index of force), flows (as an index of shortening velocities), work, power and actions of all four muscle groups becomes possible [10].

\section{The respiratory muscles during normal exercise}

The application of OEP techniques to normal subjects during exercise revealed that the pattern of respiratory muscle recruitment changed immediately in transition from rest to exercise. While no expiratory muscles were used during quiet breathing at rest, the abdominal muscles were recruited at zero-load exercise [10]. This increased abdominal pressure during expiration and because the abdominals only relaxed gradually throughout inspiration, abdominal pressure fell or remained constant during inspiration, while the abdominal wall moved ventrally. This is in striking contrast to the normal inspiratory rise in abdominal pressure during diaphragmatic descent when breathing at rest. This unloads the diaphragm so that it acts as a flow generator, while the abdominal and ribcage muscles develop the pressures to displace the abdomen, ribcage and lungs. A very simple control mechanism in which the abdominal muscles were cyclically recruited and derecruited $180^{\circ}$ out of phase with inspiratory and expiratory ribcage muscles was all that was needed to convert the diaphragm into a flow generator and prevent ribcage distortions $[10,11]$.

\section{Measurements made by OEP}

In contrast to spirometry and whole body plethysmography, OEP measures the volume of the trunk. When an independent measurement of the subdivisions of lung volume is made, and by matching OEP at maximal inspiration with total lung capacity, OEP provides a continuous breath-by-breath measurement of absolute lung volume under most conditions. Spirometry cannot do this for any length of time. Whole body plethysmography can, but only in a single body posture at rest. Thus, an important advantage of OEP is breath-by-breath tracking of absolute lung volume changes during exercise [6, 10]. If the aim is to measure oxygen consumption, OEP allows assessment of changes in lung oxygen stores in a way that commercial exercise circuits do not [12]. Under circumstances where arterial mixed venous oxygen content difference is constant, oxygen consumption is directly proportional to cardiac output by the Fick equation, so that changes in cardiac output are measurable by OEP [13].

As in whole-body plethysmography, OEP measures gas compression and decompression in the lungs, while spirometry measures only the volume of gas breathed in and out at the mouth. In addition, if blood is displaced between the trunk and extremities, this is also measured by OEP but not by spirometry or whole-body plethysmography. In normal subjects at all levels of exercise, the volumes displaced at the mouth measured by spirometry were equal to and in phase with the volumes measured by OEP [10]. The degree of respiratory muscle recruitment was moderate, so although the abdominal muscles played a crucial role in exercise, the pressures they developed were insufficient to cause significant gas compression and decompression or blood shifts between trunk and extremities. This was not the case during flowlimited exercise in normal subjects [5].

\section{The respiratory muscles during flow-limited exercise}

EFL at $\sim 1 \mathrm{~L} \cdot \mathrm{s}^{-1}$ reduced maximal exercise workload to $\sim 65 \%$ of the control maximum due to intolerable dyspnoea accompanied by substantial hypercapnia [5-7]. The expiratory pressures became excessive so there was measurable gas compression $[5,6]$. There was no difference in the degree of exercise limitation and expiratory muscle recruitment between hyperinflators and euvolumics. The high expiratory pressures during heavy exercise workloads caused tidal volumes measured by OEP to lead those measured by spirometry in phase, and to be bigger in amplitude [5].This was particularly the case during expiration; differences were small during inspiration. Because absolute gas volume was known and because calculate alveolar pressures can be calculated from transpulmonary pressures, IANDELLI et al. [5] calculated the degree of gas compression using Boyle's law. Subtracting this from the total difference between the volume expired at the mouth and the expired volume measured by OEP gave the volume of blood displaced from the trunk to the extremities. At maximal flow-limited exercise workload, this averaged $326 \mathrm{~mL}$, or $7.2 \mathrm{~mL}$ blood per $\mathrm{cmH}_{2} \mathrm{O}$ alveolar pressure [5]. Precisely where this blood came from in the trunk is unknown, but with a pulmonary capillary blood volume only slightly larger than the blood shift to the extremities, only a small contribution need come from the lung in order to affect the distribution of ventilation/perfusion ratios and impair gas exchange. This was presumably a factor in the hypercapnia that developed and that could not be explained by a decrease in alveolar ventilation calculated using anatomic dead space [6].

The average pressures generated by the abdominal muscles at maximal flow-limited exercise workloads were in the order of $40 \mathrm{cmH}_{2} \mathrm{O}$ [6]. This was in part due to the enforced slowing of shortening velocity resulting from the imposed EFL according to the force-velocity relationships of these muscles, and in part 
due to the increase in central respiratory drive secondary to the carbon dioxide retention.

In order to determine whether the high expiratory pressures decreased cardiac output, ALIVERTI et al. [13] exercised normal subjects without EFL for $4 \mathrm{~min}$ at a workload equal to their maximal workload with flow limitation, and then abruptly switched them into the Starling resistor with EFL at $\sim 0.8 \mathrm{~L} \cdot \mathrm{s}^{-1}$ while they continued to exercise to exhaustion. Using OEP, breath-by-breath oxygen consumption was measured [12], and it was assumed that the arterial mixed venous oxygen content difference did not increase. If this was the case, any changes in measured oxygen consumption were directly proportional to changes in cardiac output. If the content difference increased, any decrease in cardiac output that was measured would have been underestimated.

An immediate, highly significant decrease in cardiac output of $10 \%$ was found; this was confirmed by simultaneous estimates of a similar magnitude using the pulse contour method [14]. The latter technique indicated that cardiac output remained reduced for the remainder of the flow-limited exercise period, while breath-by-breath oxygen consumption gradually rose, presumably due to an increase in arterial mixed venous oxygen content difference. In this experiment, the expiratory pressures were not nearly as high $\left(\sim 7 \mathrm{cmH}_{2} \mathrm{O}\right.$ compared with $40 \mathrm{cmH}_{2} \mathrm{O}$ in the previous flow-limited incremental exercise tests). If the expiratory pressures had been as high, presumably cardiac output would have been further decreased. In addition, arterial oxygen saturation was decreased by $5 \%$.

It can be concluded that exercise in normal subjects with EFL imposed by a Starling resistor in the expiratory line is not only a model of COPD during exercise but also causes a condition very similar to acute cor pulmonale and acute hypercapnic respiratory failure. The excessive expiratory muscle recruitment that results decreases oxygen supply to working locomotor and respiratory muscles by $\sim 15 \%$. This is considerably more than that reported by STARK-LEYVA et al. [15] who imposed a $10-\mathrm{cmH}_{2} \mathrm{O}$ expiratory load on normal subjects during exercise. They found a decrease in cardiac output of $7 \%$ if the subject did not hyperinflate, whereas if DH occurred, the fall in cardiac output was less. For the same load, $\mathrm{DH}$ protected against adverse circulatory effects of expiratory pressures.

\section{EXERCISE IN PATIENTS WITH COPD \\ OEP measurements during exercise in COPD}

During incremental exercise in COPD, breath-by-breath OEP tracking of the volume of the trunk revealed that some patients

\begin{tabular}{|c|c|c|}
\hline & Euvolumic subjects & Hyperinflator subjects \\
\hline Wmax W & 20 & 35 \\
\hline$V^{\prime} E, w \max L \cdot \min ^{-1}$ & 35.9 & 37.9 \\
\hline$V^{\prime} \mathrm{O}_{2}, \operatorname{resp} \mathrm{mL} \cdot \mathrm{L}^{-1} \cdot \mathrm{m}^{-1}$ & 12 & 8 \\
\hline$V^{\prime} \mathrm{O}_{2}$,resp,wmax $\mathrm{mL} \cdot \mathrm{min}^{-1}$ & 430.8 & 303.2 \\
\hline
\end{tabular}

Wmax: maximal exercise workload; $V^{\prime} E$,wmax: minute ventilation at $W \max ; V^{\prime} \mathrm{O}_{2}$,resp: oxygen cost of breathing; $V^{\prime} \mathrm{O}_{2}$, resp,wmax: $V^{\prime} \mathrm{O}_{2}$,resp at Wmax. hyperinflated while others did not [3]. The euvolumics had a "normal" response to exercise in that they recruited abdominal muscles and lowered EELV in a similar manner to normal subjects during flow-limited exercise. Although this seems to contradict the findings of others [4], it should be remembered that OEP measures changes in trunk volume due to gas compression and blood shifts, while spirometric measurements do not. Differences in methodology resolve most of the discrepancies between spirometric and OEP methods of measuring DH [16].

Interestingly, however, hyperinflator subjects were found to have worse lung function than the euvolumic subjects but better exercise performance [3]. The expiratory muscle recruitment in euvolumic subjects was predominantly abdominal in a vain attempt to increase expiratory flow. This resulted in no benefit but markedly increased the work the respiratory muscles performed on the lung. At an exercise workload of $10 \mathrm{~W}$ the work performed on the lung by euvolumic subjects was on average $754 \mathrm{cmH} \mathrm{O}_{2} \cdot \mathrm{L}^{-1} \cdot \mathrm{min}^{-1}$, whereas in hyperinflator subjects it was only $277 \mathrm{cmH}_{2} \mathrm{O} \cdot \mathrm{L}^{-1} \cdot \mathrm{min}^{-1}(\mathrm{p}<0.05)$. There was no significant difference at rest.

\section{The importance of oxygen cost of breathing}

The recruitment of abdominal muscles during exercise in the euvolumic subjects increased the work performed on the lung 2.5 -fold. For this reason, the oxygen cost of breathing $\left(V^{\prime} \mathrm{O}_{2}, \mathrm{resp}\right)$ must have been greater in the euvolumic than the hyperinflator subjects. The values for $V^{\prime} \mathrm{O}_{2}$,resp in COPD range from 8 [17] to $12 \mathrm{~mL} \cdot \mathrm{L}^{-1} \cdot \mathrm{min}^{-1}$ [18] breathed. If the lower figure is assigned to the hyperinflators and the higher figure is assigned to the euvolumics and it is assumed that total body oxygen uptake $\left(V^{\prime} \mathrm{O}_{2}\right)$ and the work performed on the lung $(W \mathrm{~L})$ increased linearly with exercise workload (w), i.e. that the derivatives of $V^{\prime} \mathrm{O}_{2}$ and $W \mathrm{~L}$ with respect to $\mathrm{w}\left(\mathrm{d} V^{\prime} \mathrm{O}_{2} / \mathrm{dw}\right.$ and $\mathrm{dWL} / \mathrm{dw}$ ) were constant, the $V^{\prime} \mathrm{O}_{2}$, resp can be calculated at maximal exercise workload (wmax). This is shown in table 1. If $V^{\prime} \mathrm{O}_{2}$,resp per litre breathed and minute ventilation at wmax are known, $V^{\prime} \mathrm{O}_{2}$,resp at Wmax can be easily estimated. Similarly, from the data in [3], maximal oxygen consumption $\left(V^{\prime} \mathrm{O}_{2}, \mathrm{max}\right)$ can be estimated, as shown in table 2. This is done by calculating $\mathrm{d} V^{\prime} \mathrm{O}_{2} / \mathrm{dw}$ as the rate of increase in $V^{\prime} \mathrm{O}_{2}$ by the difference in $V^{\prime} \mathrm{O}_{2}$ at rest and the value measured at $10-\mathrm{W}$ workload and dividing by 10, multiplying this value by Wmax and adding the product to $V^{\prime} \mathrm{O}_{2}$ at rest. By subtracting $V^{\prime} \mathrm{O}_{2}$ at Wmax from $V^{\prime} \mathrm{O}_{2}$, max, the amount of oxygen available for other

\section{TABLE 2 Calculation of total body consumption}

Euvolumic subjects

Hyperinflator subjects

\begin{tabular}{|c|c|c|}
\hline$V^{\prime} \mathrm{O}_{2}$,rest $\mathrm{mL} \cdot \mathrm{min}^{-1}$ & 248 & 267 \\
\hline$V^{\prime} \mathrm{O}_{2}$ at $10 \mathrm{~W} \mathrm{~mL} \cdot \mathrm{min}^{-1}$ & 539 & 570 \\
\hline $\mathrm{dV}^{\prime} \mathrm{O}_{2} / \mathrm{dw} \mathrm{mL} \cdot \mathrm{min}^{-1} \cdot \mathrm{W}^{-1}$ & 29.1 & 30.3 \\
\hline Wmax W & 20 & 35 \\
\hline$V^{\prime} \mathrm{O}_{2}, \max \mathrm{mL} \cdot \mathrm{min}^{-1}$ & 830.0 & 1327.5 \\
\hline
\end{tabular}

$V^{\prime} \mathrm{O}_{2}$, rest: oxygen uptake at rest; $V^{\prime} \mathrm{O}_{2}$ : oxygen uptake; $d V^{\prime} \mathrm{O}_{2} / d w$ : rate of change of $V^{\prime} \mathrm{O}_{2}$ with respect to exercise workload (W); Wmax: maximal exercise workload; $V^{\prime} \mathrm{O}_{2}$, max: maximal $V^{\prime} \mathrm{O}_{2}$. 


\begin{tabular}{|c|c|c|c|}
\hline \multirow[t]{2}{*}{ TABLE 3} & \multicolumn{3}{|c|}{$\begin{array}{l}\text { Oxygen available for locomotor muscles and } \\
\text { other body tissues }\end{array}$} \\
\hline & & Euvolumic subjects & Hyperinflator subjects \\
\hline \multirow{3}{*}{\multicolumn{2}{|c|}{$\begin{array}{l}V^{\prime} \mathrm{O}_{2}, \max \mathrm{mL} \cdot \mathrm{min}^{-1} \\
V^{\prime} \mathrm{O}_{2}, \text { resp,max } \mathrm{mL} \cdot \mathrm{m}^{-1} \\
\Delta V^{\prime} \mathrm{O}_{2} \mathrm{~mL} \cdot \mathrm{m}^{-1}\end{array}$}} & 830.0 & 1327.5 \\
\hline & & -430.8 & -303.2 \\
\hline & & 399.2 & 1024.3 \\
\hline
\end{tabular}

body tissues, including exercising locomotor muscles, if the respiratory muscles receive their total demand is obtained. This is shown in table 3 .

\section{Competition between respiratory and locomotor muscles for available energy supplies}

The importance of $V^{\prime} \mathrm{O}_{2}$,resp to exercise performance is revealed by this analysis. In the euvolumic subjects, if the respiratory muscles had received their total demand, only $399.2 \mathrm{~mL}$ of oxygen per minute were left over for exercising locomotor muscles and other body tissues (just slightly more than resting oxygen consumption), whereas the hyperinflator subjects had $1024.3 \mathrm{~mL}$ of oxygen per minute available; this is more than two and a half times more than the euvolumic subjects.

A similar situation seems to exist in the response of patients with COPD to bronchodilators. ALIVERTI et al. [19] reported that postbronchodilator exercise responses fell cleanly into two groups: those whose exercise performance improved and those in whom it worsened. The latter group, like the euvolumic subjects, had strong abdominal muscle recruitment and exercise endurance time fell. The improvers did not recruit abdominal muscles strongly and, as a result, dynamically hyperinflated; their endurance times increased.

\section{CONCLUSIONS}

It seems that competition between respiratory and locomotor muscles for available energy supplies can be an important factor limiting exercise performance in COPD, both because strong, but normal, abdominal muscle recruitment can act as a Valsalva manoeuvre to decrease venous return and cardiac output, and because the large $V^{\prime} \mathrm{O}_{2}$,resp in COPD captures or demands so much of the available oxygen supply. This competition is an important pathophysiological feature of conditions such as shock, which limits energy supplies [20], and also during heavy exercise in healthy humans [21], but has not been widely recognised as a factor limiting exercise in COPD.

Evidence also indicates that lack of strong abdominal muscle recruitment and dynamic hyperinflation is a better exercise strategy in chronic obstructive pulmonary disease $[3,18]$. It leads to better exercise performance in the face of worse lung function [3], and it allows bronchodilators to improve exercise performance [19]. Furthermore, dynamic hyperinflation appears to mitigate the effects of high expiratory pressures [15]. Unfortunately, there is strong evidence that this strategy is a powerful and important factor limiting exercise in chronic obstructive pulmonary disease [4]; clearly the benefit it confers is minimal.

\section{REFERENCES}

1 Potter WA, Olafsson S, Hyatt RE. Ventilatory mechanics and expiratory flow limitation during exercise in patients with obstructive lung disease. J Clin Invest 1971; 50: 910-919.

2 Dodd DS, Brancatisano T, Engel LA. Chest wall mechanics during exercise in patients with severe chronic air-flow obstruction. Am Rev Respir Dis 1984; 129: 33-38.

3 Aliverti A, Stevenson N, Dellaca RL, Lo Mauro A, Pedotti A, Calverly PMA. Regional chest wall volumes during exercise in chronic obstructive lung disease. Thorax 2004; 59: 210-216.

4 O'Donnell DE, Revill SM, Webb KA. Dynamic hyperinflation and exercise intolerance in chronic obstructive pulmonary disease. Am J Respir Crit Care Med 2001; 164: 770-777.

5 Iandelli I, Aliverti A, Kayser B, et al. Determinants of exercise performance in normal men with externally applied expiratory flow limitation. J Appl Physiol 2002; 92: 1943-1952.

6 Aliverti A, Iandelli I, Duranti R, et al. Respiratory muscle dynamics and control during exercise with externally applied expiratory flow limitation. J Appl Physiol 2002; 92: 1953-1963.

7 Kayser B, Sliwinski P, Yan S, Tobiasz M, Macklem PT. Respiratory effort sensation during exercise with induced expiratory-flow limitation in healthy humans. $J \mathrm{Appl}$ Physiol 1997; 83: 936-947.

8 Ward ME, Ward JW, Macklem PT. Analysis of human chest wall motion using a two-compartment rib cage model. J Appl Physiol 1992; 72: 1338-1347.

9 Cala SJ, Kenyon C, Ferrigno G, et al. Chest wall and lung volume estimation by optical reflectance motion analysis. $J$ Appl Physiol 1996; 81: 2680-2689.

10 Aliverti A, Cala SJ, Duranti R, et al. Human respiratory muscle actions and control during exercise. J Appl Physiol 1997; 83: 1256-1269.

11 Kenyon CM, Cala SJ, Yan S, et al. Rib cage mechanics during quiet breathing and exercise in humans. J Appl Physiol 1997; 83: 1242-1255.

12 Aliverti A, Kayser B, Macklem PT. Breath-by-breath assessment of alveolar gas stores and exchange. J Appl Physiol 2004; 96: 1464-1469.

13 Aliverti A, Dellacà RL, Lotti $\mathrm{P}$, et al. Influence of expiratory flow-limitation during exercise on systemic oxygen delivery in humans. Eur J Appl Physiol 2005; 95: 229-242.

14 Wesseling KH, Jansen JR, Settels JJ, Schreuder JJ. Computation of aortic flow from pressure in humans using a nonlinear, three-element model. J Appl Physiol 1993; 74: 2566-2573.

15 Stark-Leyva KN, Beck KC, Johnson BD. Influence of expiratory loading and hyperinflation on cardiac output during exercise. J Appl Physiol 2004; 96: 1920-1927.

16 Macklem PT. Exercise in COPD: damned if you do, damned if you don't. Thorax 2005; 60: 887-888.

17 Oelberg DA, Medoff BD, Markowitz DH, Pappagianopoulos PP, Ginns LC, Systrom DM. Systemic oxygen extraction during incremental exercise in patients with severe chronic obstructive pulmonary disease. Eur J Appl Physiol Occup Physiol 1998; 78: 201-207. 
18 Levison H, Cherniack RM. Ventilatory cost of exercise in chronic obstructive pulmonary disease. J Appl Physiol 1968; 25: 21-27.

19 Aliverti A, Rodger K, Dellaca RL, et al. Effect of salbutamol on lung function and chest wall volumes at rest and during exercise in COPD. Thorax 2005; 60: 916-924.
20 Roussos C, Macklem PT. The respiratory muscles. N Engl J Med 1982; 307: 786-797.

21 Harms CA, Wetter TJ, McClaran SR, et al. Effects of respiratory muscle work on cardiac output and its distribution during maximal exercise. J Appl Physiol 1998; 85: 609-618. 